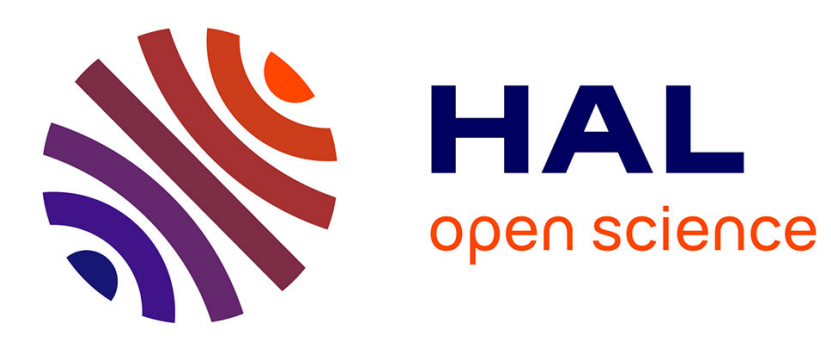

\title{
Psycho-Physiological Responses to Repeated-Sprint Training in Normobaric Hypoxia and Normoxia
}

Franck Brocherie, Olivier Girard, Grégoire P. Millet

\section{To cite this version:}

Franck Brocherie, Olivier Girard, Grégoire P. Millet. Psycho-Physiological Responses to RepeatedSprint Training in Normobaric Hypoxia and Normoxia. International Journal of Sports Physiology and Performance, 2016, 12 (1), pp.115-123. 10.1123/ijspp.2016-0052 . hal-01491040

\section{HAL Id: hal-01491040 https://hal-insep.archives-ouvertes.fr/hal-01491040}

Submitted on 16 Mar 2017

HAL is a multi-disciplinary open access archive for the deposit and dissemination of scientific research documents, whether they are published or not. The documents may come from teaching and research institutions in France or abroad, or from public or private research centers.
L'archive ouverte pluridisciplinaire HAL, est destinée au dépôt et à la diffusion de documents scientifiques de niveau recherche, publiés ou non, émanant des établissements d'enseignement et de recherche français ou étrangers, des laboratoires publics ou privés. 
"Psycho-Physiological Responses to Repeated-Sprint Training in Normobaric Hypoxia and Normoxia"

Note. This article will be published in a forthcoming issue of the International Journal of Sports Physiology and Performance. The article appears here in its accepted, peer-reviewed form, as it was provided by the submitting author. It has not been copyedited, proofread, or formatted by the publisher.

Section: Original Investigation

Article Title: Psycho-Physiological Responses to Repeated-Sprint Training in Normobaric Hypoxia and Normoxia

Authors: Franck Brocherie ${ }^{1,2}$, Grégoire P. Millet ${ }^{1,2}$, and Olivier Girard ${ }^{1,2,3}$

Affiliations: ${ }^{1}$ ISSUL, Institute of Sports Sciences, University of Lausanne, Switzerland. ${ }^{2}$ Department of Physiology, Faculty of Biology and Medicine, University of Lausanne, Switzerland. ${ }^{3}$ ASPETAR, Orthopaedic and Sports Medicine Hospital, Athlete Health and Performance Research Centre, Doha, Qatar.

Journal: International Journal of Sports Physiology and Performance

Acceptance Date: April 4, 2016

(C)2016 Human Kinetics, Inc.

DOI: $\underline{\text { http://dx.doi.org/10.1123/ijspp.2016-0052 }}$ 
"Psycho-Physiological Responses to Repeated-Sprint Training in Normobaric Hypoxia and Normoxia"

by Brocherie F, Millet GP, Girard O

International Journal of Sports Physiology and Performance

(C) 2016 Human Kinetics, Inc.

Title: Psycho-physiological responses to repeated-sprint training in normobaric hypoxia and normoxia

Running head: Repeated-sprint training and psycho-physiological strain

Submission type: Original investigation

Authors:

Franck Brocherie ${ }^{1,2}$, Grégoire P. Millet ${ }^{1,2}$, Olivier Girard ${ }^{1,2,3}$

Affiliations:

1. ISSUL, Institute of Sports Sciences, University of Lausanne, Switzerland,

2. Department of Physiology, Faculty of Biology and Medicine, University of Lausanne, Switzerland,

3. ASPETAR, Orthopaedic and Sports Medicine Hospital, Athlete Health and Performance Research Centre, Doha, Qatar.

Corresponding author:

Franck Brocherie

ISSUL, Building Geopolis, Campus Dorigny, University of Lausanne, CH-1015, Lausanne, Switzerland.

Ph. +41216923294

Fax. +41216923293

Email franck.brocherie@unil.ch

Abstract word count: 250

Text only word count: 3185

Number of figures: 3

Number of tables: 2 
"Psycho-Physiological Responses to Repeated-Sprint Training in Normobaric Hypoxia and Normoxia"

by Brocherie F, Millet GP, Girard O

International Journal of Sports Physiology and Performance

(C) 2016 Human Kinetics, Inc.

\section{ABSTRACT}

PURPOSE: We compared psycho-physiological responses to six repeated-sprint sessions in normobaric hypoxia (RSH) and normoxia (RSN) in team-sport athletes during a 2-wk 'live high-train low' training camp. METHODS: While residing under normobaric hypoxia $(\geq 14$ h.d $\mathrm{d}^{-1} ; \mathrm{FiO}_{2}$ 14.5-14.2\%), twenty-three lowland elite field hockey players performed, in addition to their usual training, six sessions $(4 \times 5 \times 5$-s maximal sprints; $25 \mathrm{~s}$ passive recovery; 5 min rest) under either normobaric hypoxia $\left(\mathrm{FiO}_{2} \sim 14.5 \%\right)$ or normoxia $\left(\mathrm{FiO}_{2}\right.$ 21\%). Sprint 1 and 5 times, physiological strain [heart rate (HR), arterial oxyhemoglobin saturation $\left.\left(\mathrm{SpO}_{2}\right)\right]$ and perceptual responses (overall peripheral discomfort, difficulty breathing and lower-limb discomfort) were monitored. RESULTS: During the first session, HR increased across sets $(\mathrm{P}<0.001)$, independently of the conditions while $\mathrm{SpO}_{2}$ was globally lower $(\mathrm{P}<0.001)$ for RSH (averaged value: $91.9 \pm 1.2 \%)$ vs. RSN $(96.9 \pm 0.6 \%)$. Thereafter, $\mathrm{SpO}_{2}$ and $\mathrm{HR}$ remained similar across sessions for each condition. While first sprint time remained similar, last sprint time and fatigue index significantly decreased across sets $(\mathrm{P}<0.01)$ and sessions $(\mathrm{P}<0.05)$ but not between conditions. Ratings of overall perceived discomfort, difficulty breathing and lower-limb discomfort were higher $(\mathrm{P}<0.05)$ in RSH vs. RSN at the first session. During subsequent sessions, overall perceived discomfort (time $(\mathrm{P}<0.001)$ and condition $(\mathrm{P}<0.05)$ effects), difficulty breathing (time effect; $\mathrm{P}<0.001)$ and lower-limb discomfort (condition $(\mathrm{P}<0.001)$ and interaction $(\mathrm{P}<0.05)$ effects) values decreased to a larger extent in RSH vs. RSN. CONCLUSION: Despite higher hypoxiainduced physiological and perceptual strain during the first session, perceptual responses improved thereafter in RSH so as not to differ from RSN. This indicates an effective 'acclimation' and tolerance to this innovative training.

Key words: Acclimation, altitude, high-intensity exercise, team sports, perceived peripheral discomfort, ratings of perceived exertion. 
"Psycho-Physiological Responses to Repeated-Sprint Training in Normobaric Hypoxia and Normoxia"

by Brocherie F, Millet GP, Girard O

International Journal of Sports Physiology and Performance

(C) 2016 Human Kinetics, Inc.

\section{Introduction}

A growing number of team-sport athletes are using altitude training with the belief that it can promote greater physiological adaptations compared to similar training conducted near sea level, in turn further improving in-game physical performance ${ }^{1}$. Time constraints during the yearly competitive calendar render the implementation of 'traditional' altitude training (e.g., 3 weeks of 'live high-train high' at natural altitude or 'live high-train low' in altitude dormitories) challenging. Innovative hypoxic methods such as repeated-sprint training in hypoxia $(\mathrm{RSH})$, defined as the repetition of several short $(\leq 30 \mathrm{~s})$ 'all-out' exercise bouts in deprived- $\mathrm{O}_{2}$ environments interspersed with incomplete recoveries (exercise-to-rest ratio $\leq 1: 5)^{2}$, encounter an expanding popularity in the team-sport community ${ }^{3}$. By adding hypoxic stimuli to repeated-sprint training (2-6 weeks), larger benefits have been reported on in-game physical performance-related variables [e.g., Yo-Yo intermittent recovery and/or repeated-sprint ability (RSA) tests] when compared to similar training in normoxia (RSN) ${ }^{4,5}$.

In the available literature, most of RSH studies are laboratory-based through the use of standard hypoxic facilities (e.g., $\mathrm{O}_{2}$-filtration chambers/tents or breathing hypoxic mixtures with a mask) while sprinting on a cycle ergometer ${ }^{6}$, a treadmill ${ }^{5}$, over-ground using short shuttles ${ }^{7}$ or when treadmill and over-ground runs were combined ${ }^{4}$. At top level, coaches and athletes are naturally looking for sport-specific exercises with a direct relevance (high ecological validity) to their programmes. New technologies such as the mobile inflatable hypoxic marquees ${ }^{8}$ now offer advancements of hypoxic training practical applications, notably with the opportunity to train (e.g., repeated sprinting over $\sim 30 \mathrm{~m}$, smallsided games, resistance training in hypoxia) under field-based hypoxic conditions (e.g., on natural/artificial grass in footballers wearing their football cleats). We have recently demonstrated superior effects of training inside these marquees using a $\mathrm{RSH}$ paradigm as compared to RSN, when combined with residing at moderate simulated altitude $\left(\geq 14{\mathrm{~h} . \mathrm{d}^{-1} \text { at }}^{-1}\right.$ 
"Psycho-Physiological Responses to Repeated-Sprint Training in Normobaric Hypoxia and Normoxia"

by Brocherie F, Millet GP, Girard O

International Journal of Sports Physiology and Performance

(c) 2016 Human Kinetics, Inc.

a simulated altitude of 2800-3000 m), for improving RSA in elite field-hockey players during an in-season 2-wk training camp ${ }^{9}$.

Determining the day-to-day athletes' tolerance to the prescribed training load is fundamental for optimal periodization and adaptations (i.e., maximize performance gains and minimize overreaching or injury risks) ${ }^{10}$. In team-sports, heart rate (HR) and rate of perceived exertion (RPE) are common indicators of players' degree of physical strain ${ }^{11}$. Although the RPE is a recognized marker of subjective assessment of exercise intensity, particularly if this is known by the participants ${ }^{12}$, we have recently reported that the perception of peripheral discomfort is independent from the sense of effort during submaximal and maximal cycling bouts, despite a hypoxic-induced exaggeration of the physiological responses and higher ratings of perceived difficulty breathing ${ }^{13}$. Single sprint performance requires, by nature, a maximal 'sense of effort' or 'perception of effort' (i.e., depending on the definition used by authors ${ }^{14}$ ), but produces quite moderate perceived discomfort values due to mild sensory inputs from heart, lungs and active muscles ${ }^{15}$. However, when such maximal efforts are repeated (i.e., at a remaining maximal 'sense of effort') peripheral discomfort increases substantially ${ }^{15}$. While this highlights the necessity to distinguish and individually report the accompanying perceptions of perceived discomfort (i.e., overall peripheral discomfort, difficulty breathing and lower-limb discomfort), our understanding of responses to RSH training so far is limited to mucosal immune function ${ }^{16}$.

Our aim was therefore to compare changes in sprint performance along with physiological [HR and arterial oxyhemoglobin saturation $\left.\left(\mathrm{SpO}_{2}\right)\right]$ and perceptual responses (RPE, overall peripheral discomfort, difficulty breathing and lower-limb discomfort) to six repeated-sprint sessions in normobaric hypoxia (RSH) and normoxia (RSN) in elite teamsport players, conducted during a 2-wk 'altitude' training camp. 
"Psycho-Physiological Responses to Repeated-Sprint Training in Normobaric Hypoxia and Normoxia"

by Brocherie F, Millet GP, Girard O

International Journal of Sports Physiology and Performance

(C) 2016 Human Kinetics, Inc.

\section{Methods}

\section{Participants}

After being informed of the potential risks and benefits involved, twenty-three lowland elite field hockey players (Table 1) provided their written consent to participate in this study. The experiment was approved by the Anti-Doping Lab Qatar institutional review board (Agreement SCH-ADL-070) and conformed to the current Declaration of Helsinki guidelines. Participants practiced $\sim 7.0-9.0$ h. $\mathrm{wk}^{-1}$ of training (5-7 weekly sessions) and competitive matches (1-2 matches per week) during the season. Training sessions included aerobic, anaerobic and strength training in isolation or combined with sport-specific training (i.e., technical and tactical skills). All participants were born and raised at altitudes $<1000 \mathrm{~m}$ and had not travelled to elevations $>2000 \mathrm{~m}$ for more than $48 \mathrm{~h}$ in the 6 months prior to the study.

\section{Experimental design/Protocol}

This study is part of a large experiment conducted during an in-season competition phase (i.e., December-February, including the winter break) and additional details about the research design can be find elsewhere ${ }^{9}$. Participants were matched for initial fitness level and playing position and randomly assigned to a normobaric hypoxia $(\mathrm{RSH}, \mathrm{n}=11)$ or normoxia (RSN, $\mathrm{n}=12$ ) group. In addition to their usual field hockey practice, all participants undertook six repeated-sprint training sessions (at least $36 \mathrm{~h}$ apart), while residing under

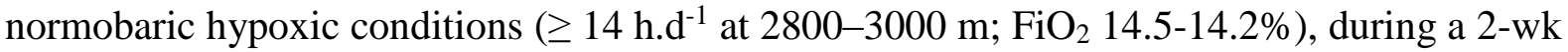
in-season training camp.

Sprint performance was evaluated during RSH/RSN training sessions (Fig. 1). Before and after each of the four sets of each training session (see below), several variables were collected to assess psycho-physiological strain associated with the completion of the 
"Psycho-Physiological Responses to Repeated-Sprint Training in Normobaric Hypoxia and Normoxia"

by Brocherie F, Millet GP, Girard O

International Journal of Sports Physiology and Performance

(c) 2016 Human Kinetics, Inc.

proposed intervention: $\mathrm{HR}$ and $\mathrm{SpO}_{2}$ together with $\mathrm{RPE}$, overall perceived peripheral discomfort, lower-limb discomfort and difficulty breathing.

\section{Specific repeated-sprint training}

Each session lasted $~ 50$ min, including a 15-min warm-up [i.e., low-intensity running with athletic (e.g., skipping, high knee runs) and acceleration drills (e.g., shorts bursts of progressive accelerations and maximal 10-m straight-line sprints)], the repeated-sprint training routine and a 10-min recovery phase (i.e., cool down and passive stretching). Specifically, the repeated-sprint training routine included four sets of $5 \times 5$-s maximal sprints in alternating directions interspersed with $25 \mathrm{~s}$ of passive recovery with 5 min of standing rest between sets. With an exercise-to-rest ratio of 1:5, up to six players trained together with an invariant execution order. Practically, each participant departed for sprinting every $5 \mathrm{~s}$, as controlled by audio beeps. Because of space restriction inside the marquee, they had to decelerate on a short distance (i.e., $\sim 10 \mathrm{~m}$ ). During all training sessions, participants were constantly reminded to assume a standing ready position for $2 \mathrm{~s}$ before starting, and were vigorously encouraged to perform 'all-out' efforts in trying to reach peak acceleration and to maintain the highest possible running speed for every sprint.

Training sessions were completed on an indoor synthetic grass inside a mobile inflatable simulated hypoxic equipment (Altitude Technology Solutions Pty Ltd, Brisbane, Queensland, Australia), as previously described ${ }^{8}$. Briefly, it comprised a polyvinyl chloride inflatable running lane tunnel (length $=45 \mathrm{~m}$, width $=1.8 \mathrm{~m}$ and height $=2.5 \mathrm{~m}$ ) and a stateof-the-art hypoxic trailer (55 kW screw compressor), generating over $3000 \mathrm{Lpm}$ of hypoxic air with $\mathrm{FiO}_{2}$ between $21 \%$ and $10 \%$ (a simulated altitude up to $5100 \mathrm{~m}$ ). Temperature and humidity were maintained constant at $\sim 25^{\circ} \mathrm{C}$ and $\sim 55 \%$ relative humidity, owing to the exercise-generated humidity compensated by the dry air supplied inside the marquee. For 
"Psycho-Physiological Responses to Repeated-Sprint Training in Normobaric Hypoxia and Normoxia"

by Brocherie F, Millet GP, Girard O

International Journal of Sports Physiology and Performance

(C) 2016 Human Kinetics, Inc.

$\mathrm{RSH}$, ambient air was mixed with nitrogen (from pressurized tanks) to reduce $\mathrm{FiO}_{2}$ to $\sim 14.5 \%$ in order to simulate an altitude of $\sim 3000 \mathrm{~m}$. While up to six participants trained simultaneously in the marquee (Fig. 1), they were all assigned to different teammates during the six sessions, in order to reinforce motivation. For blinding purposes, participants were told (head coach request) that they were all training under hypoxic conditions but had no accurate information about actual simulated altitude levels. The total hypoxic exposure corresponded exactly to the training duration, i.e., with RSH / RSN participants breathing hypoxic / normoxic air from the time of entrance to exit of the marquee.

\section{Sprinting timing}

During training, the straight-line sprints were performed back and forth. Sprint performance (timing) during the first and the last (sprint 1 and 5, respectively) sprint of each of the four sets was measured to the nearest $0.01 \mathrm{~s}$ using photocells connected to an electronic timer (Polifemo Radio light, Microgate, Bolzano, Italy). Timing gates were positioned at 0and 20-m distance intervals, with additional turned-off gates placed at a distance of $\sim 35 \mathrm{~m}$ (corresponding to $\sim 5$-s duration sprint) in order to make sure participants produced maximal effort (i.e., no deceleration) throughout each sprint bout. Performance fatigability (i.e., percent increase in time between the fastest and slowest sprints) was calculated using the following formula:

Fatigue index $(\mathrm{FI}, \%)=[(\operatorname{sprint} 5-$ sprint 1$) / \operatorname{sprint} 1] \times 100{ }^{17}$.

\section{Physiological responses to exercise}

$\mathrm{HR}$ and $\mathrm{SpO}_{2}$

$\mathrm{HR}$ and $\mathrm{SpO}_{2}$ were monitored (i.e., participants were blinded to values), respectively, via a wireless Polar monitoring system (Polar Electro Oy, Kempele, Finland) and noninvasive pulse oximeter using a finger probe (GO2TM Achieve 9570-A, Nonin, Plymouth, 
"Psycho-Physiological Responses to Repeated-Sprint Training in Normobaric Hypoxia and Normoxia"

by Brocherie F, Millet GP, Girard O

International Journal of Sports Physiology and Performance

(C) 2016 Human Kinetics, Inc.

MN, USA). These values were first recorded prior to and immediately upon completion of the standardized warm-up (i.e., 15 min following entry to the mobile hypoxic marquee). Afterwards, physiological responses were collected exactly $1 \mathrm{~min}$ and $4 \mathrm{~min}$ into the 5 -min resting period following each of the four repeated sprints sets.

\section{Perceived Exertion Measures}

Rating of perceived exertion and training load

As an index of overall feeling of subjective perceived exertion, session RPE was assessed within $10 \mathrm{~min}$ of completing each training session with the 6-20 Borg scale. Training loads (arbitrary units, a.u.) were calculated for all players as total training session duration (min) $\times$ session RPE ${ }^{18}$.

\section{Perceived discomfort scales}

Based on modified Borg CR10 scales, ratings of overall perceived peripheral discomfort, perceived lower-limb discomfort and perceived difficulty breathing ${ }^{13}$ were recorded (invariant order) at the same time intervals as physiological responses (i.e., $1 \mathrm{~min}$ and $4 \mathrm{~min}$ after each of the four exercise sets). Beforehand, players were thoroughly instructed that the 'perceived discomfort' scales, visible to participants at all times, were used to evaluate their subjective perception of (i) overall peripheral discomfort ('How uncomfortable do you feel overall?'), (ii) specific lower-limb discomfort ('How uncomfortable do your legs feel?') and (iii) difficulty breathing ('How uncomfortable does it feel to breathe?') (Fig. 1).

\section{Statistical analysis}

Normal distribution was examined using Kolmogorov-Smirnov normality test. Separate two-way analyses of variance (ANOVA), with repeated measures for condition (RSH vs. RSN), time [(session 1, 2, 3, 4, 5 vs. 6) or (set 1, 2, 3 vs. 4)] and possible interaction 
"Psycho-Physiological Responses to Repeated-Sprint Training in Normobaric Hypoxia and Normoxia"

by Brocherie F, Millet GP, Girard O

International Journal of Sports Physiology and Performance

(C) 2016 Human Kinetics, Inc.

between these two factors was conducted. When ANOVA revealed a significant effect, post hoc comparisons were made using the Bonferroni method. Averaged values (mean of the 6 sessions) and percentage changes (relative to session 1) were compared between the two groups using a one-way ANOVA. For each ANOVA, effect size (ES) was calculated (Cohen's $d$ ) with the following criteria: an ES of $<0.2$ is classified as a 'trivial', $0.2-0.4$ as a 'small', $0.5-0.7$ as a 'moderate' and $>0.8$ as a 'large' effect. Data are presented as means \pm SD. Statistical analyses were performed using Sigmaplot 11.0 software (Systat Software, San Jose, CA, USA). Statistical significance was set at $\mathrm{P}<0.05$.

\section{Results}

Prior to entering the mobile hypoxic marquee, $\mathrm{HR}$ and $\mathrm{SpO}_{2}$ did not differ among conditions $(\mathrm{P}=0.06$ and 0.12 , respectively) and between sessions $(\mathrm{P}=0.15$ and 0.23$)$ (Fig. 2). Following the 15-min warm-up period, there was a hypoxia-induced increase in HR and decrease in $\mathrm{SpO}_{2}$ values (both $\mathrm{P}<0.001$ ). Sprint performance outcomes along with psychophysiological responses to RSH and RSN are presented in Figs. 2 and 3 with the corresponding statistical analyses (i.e., averaged data of all sets) displayed in Table 2.

During the first session, $\mathrm{SpO}_{2}$ remained depressed in $\mathrm{RSH}(\mathrm{P}<0.001)$ while $\mathrm{HR}$ increased across sets $(\mathrm{P}<0.001)$, independently of the conditions (Fig. 2). Thereafter, both $\mathrm{SpO}_{2}$ and $\mathrm{HR}$ remained similar across sessions for each condition. While first sprint time was similar between conditions, sets and sessions (Fig. 2 and Table 2), last sprint time and sprint 1-5 fatigue index significantly decreased across sets and sessions (time effect, $\mathrm{P}<0.01$ and $<$ 0.05 , respectively) leading to significant lower averaged sprint 5 time values $(\mathrm{P}<0.001)$ in RSH compared with RSN (Fig. 2 and Table 2). At the first session, ratings of overall perceived discomfort, difficulty breathing and lower-limb discomfort were higher $(\mathrm{P}<0.05)$ in RSH compared with RSN (Fig. 3 and Table 2), with an effect of time $(\mathrm{P}<0.001)$ on 
"Psycho-Physiological Responses to Repeated-Sprint Training in Normobaric Hypoxia and Normoxia"

by Brocherie F, Millet GP, Girard O

International Journal of Sports Physiology and Performance

(C) 2016 Human Kinetics, Inc.

ratings of overall perceived discomfort and difficulty breathing. During subsequent sessions, overall perceived discomfort (time and condition effects; $\mathrm{P}<0.001$ and 0.05 , respectively), difficulty breathing (time effect; $\mathrm{P}<0.001$ ) and lower-limb discomfort (condition and interaction effects; $\mathrm{P}<0.001$ and 0.05 , respectively) values decreased to a larger extent in RSH vs. RSN (Fig. 3 and Table 2).

While session RPE did not differ between conditions at the first session $(\mathrm{P}=0.10)$, perceived exertion was significantly lower $(\mathrm{P}<0.05)$ in $\mathrm{RSH}$ compared with $\mathrm{RSN}$, with a significant different magnitude of change $(\mathrm{P}<0.05)$ (Table 2). Statistical analysis revealed no main effect of condition $(\mathrm{P}=0.93)$, time $(\mathrm{P}=0.80)$ and interaction $(\mathrm{P}=0.18)$ for training load (pooled values for the six sessions: $592 \pm 68$ and 593 \pm 69 in RSH and RSN, respectively) monitored during the 2-wk period.

\section{Discussion}

The main findings of the present investigation were as follows: (i) despite a higher hypoxia-induced physiological stress (i.e., $\mathrm{SpO}_{2}$ ) and higher-perceived ratings, sprint performance responses were comparable for RSH and RSN at the first session; and (ii) as training sessions progressed, perceptual responses improved for $\mathrm{RSH}$, indicative of an effective altitude 'acclimation'. Effective tolerance to this innovative RSH training was accompanied by an improved repeated sprints performance (i.e., lower averaged sprint 5 time).

\section{Sprint performance}

Single sprint performance of short duration $(<10 \mathrm{~s})$ is generally well-preserved under hypoxic (2000-3800 m) vs. normoxic conditions ${ }^{19}$. In line with these observations, in our study, the first sprint performance was also similar between conditions, sets and sessions. This is presumably due to an increase in the rate of anaerobic energy release, which 
"Psycho-Physiological Responses to Repeated-Sprint Training in Normobaric Hypoxia and Normoxia"

by Brocherie F, Millet GP, Girard O

International Journal of Sports Physiology and Performance

(C) 2016 Human Kinetics, Inc.

compensates for the limited oxidative contribution when sprinting in $\mathrm{O}_{2}$-deprived environments ${ }^{20}$. As expected, as sprints were repeated, a significant time effect was found for last sprint time and performance fatigability, which may primarily relate to a decline in adenosine triphosphate resynthesis from phosphocreatine hydrolysis and non-oxidative glycolysis ${ }^{17}$. However, whereas hypoxia has been associated with earlier and larger RSA performance decrements ${ }^{19,21}$, in our study, no difference was observed between conditions. These discrepant findings may result from the smaller number of sprints repetition within a set and/or the shorter distances monitored (i.e., first and last effort of 5 repetitions over $20 \mathrm{~m}$ ) $v s$. those actually completed (5-s sprints or $\sim 30 \mathrm{~m}$ sprints distance). This methodological choice was guided by the ease of comparisons with our companion paper where a $8 \times 20 \mathrm{~m}$ RSA test was used during pre- and post-tests ${ }^{9}$. Regardless, the significant improvement in sprint 5 performance over successive sessions confirms that RSH (and to a lesser extent RSN) is an effective time-efficient training strategy to improve RSA performance ${ }^{22}$. This corroborates previous findings from our research group using isolated- ${ }^{6}$, mixed- ${ }^{4}$ or combined-RSH training 9 .

\section{Physiological and perceptual responses}

In the present study, exposure to hypoxia during training (i.e., $\mathrm{RSH}$ ) induced lower $\mathrm{SpO}_{2}$ values compared to similar training near sea level in normoxia (i.e., RSN), also in line with available $\mathrm{RSH}$ literature ${ }^{4,5,19}$. Lower $\mathrm{SpO}_{2}$ values are generally accompanied by increased values for $\mathrm{HR}$, minute ventilation and $\mathrm{O}_{2}$ debt ${ }^{19}$. Although $\mathrm{HR}$ is not always a valid marker for prolonged anaerobic exercise, in the present study, HR increased with exercise and across sets. When ten trained male team-sport athletes completed 3 sets of repeated sprints $(9 \times 4 \mathrm{~s})$ on a non-motorized treadmill at sea level and at simulated altitudes of 2000, 3000, and $4000 \mathrm{~m}$, total work across all sets was highest at sea level with also 
"Psycho-Physiological Responses to Repeated-Sprint Training in Normobaric Hypoxia and Normoxia"

by Brocherie F, Millet GP, Girard O

International Journal of Sports Physiology and Performance

(C) 2016 Human Kinetics, Inc.

correspondingly lower mechanical performance at each successive altitude ${ }^{21}$. In line with our study, however, HR values did not differ between conditions. Potentially different time points for measuring HR values during recovery periods post-exercise may have led to different HR readings between conditions.

In addition to an exacerbated rate of peripheral fatigue development ${ }^{23,24}$, an acute repeated-sprint exercise in hypoxia is known to elevate subjective fatigue sensations compared to normoxia ${ }^{13,24}$. Accordingly, the higher overall session RPE and difficulty breathing perceived in RSH compared with RSN at the first session might relate to the higher ventilation response that is generally observed for any given absolute exercise intensity in hypoxia ${ }^{25}$. This was further accompanied by higher leg discomfort observed in RSH compared with RSN at the first session, which possibly reflects the greater accumulation of metabolic by-products (e.g., blood lactate concentration) ${ }^{26}$ when repeated sprints were performed under acute normobaric hypoxia 17, 19, 21, 23, 24. Although blood lactate concentration was not measured here, larger values under RSH may have stimulated the sensory feedback from group III/IV muscle afferents to a larger extent ${ }^{27}$, as previously observed after arterial occlusion ${ }^{28}$. Bearing in mind that these neurons play a twofold role i.e., limiting motoneuronal output, thereby modulating central fatigue; and/or enhancing circulatory and ventilatory response, thereby preventing peripheral fatigue - quantifying their influence in the regulation of the cardiorespiratory response to RSH deserves further attention. That said, the higher perceptual responses (RPE, overall peripheral discomfort, difficulty breathing and lower-limb discomfort) observed in RSH vs. RSN at the first session (acute effect) were attenuated from the second session onwards with essentially similar values in reference to RSN over the remaining five sessions ('acclimation' effect). This is contrasting with previous findings demonstrating that normobaric hypoxia and exercise when combined exacerbate perceived levels of exertion ${ }^{25}$. This discrepancy may be due to 
"Psycho-Physiological Responses to Repeated-Sprint Training in Normobaric Hypoxia and Normoxia"

by Brocherie F, Millet GP, Girard O

International Journal of Sports Physiology and Performance

(C) 2016 Human Kinetics, Inc.

difference in exercise mode between studies (i.e., repeated sprints vs. Wingate-based highintensity training vs. 4-6 $\times 30 \mathrm{~s}$ of 'all-out' cycling efforts). Regardless, the attenuated perceptual responses reported in $\mathrm{RSH}$ after the initial session are likely due to an improved tolerance to the hypoxic stimulus, possibly via an increased hypoxic ventilatory response mediated by improved chemosensitivity 29,30 . One cannot rule out that the prolonged exposure to hypoxia during the nights has improved the chemosensitivity and therefore accelerated the 'acclimation' during the RSH sessions.

Despite lower $\mathrm{SpO}_{2}$ values in $\mathrm{RSH}$ vs. RSN, ratings of RPE, overall peripheral discomfort and difficulty breathing remained rather low even under hypoxic exposure (i.e., values never exceeding 7 on CR10 scales), which may explain why we failed to report significant difference between the two conditions after the first 'acclimation' session. On the one hand, it could be argued that longer sprints, shorter recoveries or combination of both (i.e., more intense exercise-to-rest ratios) and/or the use of more severe hypoxic conditions [also causing larger performance fatigability; ${ }^{21}$ ] might lead to significant difference between RSH and RSN. On the other hand, this also suggests that a manipulation of such trainingrelated factors (i.e., exercise-to-rest ratios and/or hypoxic levels) is necessary to optimize individual responses to $\mathrm{RSH}^{31}$. The increased lower-limb discomfort observed in RSN may be attributed to possible inter-session fatigue appearance. However, this would have also been observed in RSH, unless hypoxic 'tolerance' had lessened this phenomenon. Despite being constantly reminded about what perceived lower-limb discomfort actually measured, it remains possible that several players rated the discomfort of their legs with a variety of sensations - e.g., muscle pain, joint and foot pressure, and muscle tension ${ }^{7}$ - experienced during repeated sprinting, not just how uncomfortable their legs felt.

Previous studies have documented that short-term intermittent normobaric/hypobaric hypoxia (e.g., 1-2 h.day ${ }^{-1}$ over 7-10 consecutive days) leads to ventilatory 
"Psycho-Physiological Responses to Repeated-Sprint Training in Normobaric Hypoxia and Normoxia"

by Brocherie F, Millet GP, Girard O

International Journal of Sports Physiology and Performance

(C) 2016 Human Kinetics, Inc.

'acclimation/acclimatization' to hypoxia, characterized by a progressive recovery in physiological functions (i.e., increase in $\mathrm{SpO}_{2}$ and decrease in $\mathrm{HR}$ values) during hypoxic exercise ${ }^{32}$. In this study, however, $\mathrm{SpO}_{2}$ remained stable and the decrease in HR was not significant across sessions notably for $\mathrm{RSH}$, mainly due to high individual variability in response to hypoxic exercise. Pending confirmatory research, it is possible that an increased hypoxic ventilatory response may have been counteracted by other likely RSH-induced physiological mechanisms as hemodynamic ${ }^{33}$ and/or muscular adaptations ${ }^{34}$.

\section{Practical applications}

We observed that ratings of overall perceived discomfort, difficulty breathing and lower-limb discomfort decreased after the first RSH session to reach comparable values with RSN, while sprint performance achieved with or without hypoxic exposure followed similar trends across sessions. Together with larger performance improvement (i.e., lower averaged sprint 5 time), these positive perceived adaptations for RSH may have played a role in the post-intervention performance gains ${ }^{9}$. This indicates that the proposed RSH modality (i.e., four sets of $5 \times 5$-s maximal sprints interspersed with $25 \mathrm{~s}$ of passive recovery with 5 min of standing rest between sets at $\mathrm{FiO}_{2} \sim 14.5 \% / \sim 3000 \mathrm{~m}$ ), combined with normobaric hypoxic residence ( $\geq 14$ h.d $\mathrm{d}^{-1}$ at $\left.\mathrm{FiO}_{2} 14.5-14.2 \% ; 2800-3000 \mathrm{~m}\right)$, is sufficient in severity, duration and/or frequency to elicit a significant hypoxic 'acclimation'. This study therefore adds to the recent results of Born et al. ${ }^{16}$, where mucosal immune function was not further impaired with $\mathrm{RSH}$, by showing that players tolerance to RSH is effective after only one session. Since RSH does not negatively alter psycho-physiological responses when compared to RSN, coaches and their athletes are encouraged to implement such time-efficient hypoxic interventions in order to gain a competitive edge ${ }^{9}$. By closely monitoring training loads and psycho-physiological responses of players in response to each session, this investigation 
"Psycho-Physiological Responses to Repeated-Sprint Training in Normobaric Hypoxia and Normoxia"

by Brocherie F, Millet GP, Girard O

International Journal of Sports Physiology and Performance

(C) 2016 Human Kinetics, Inc.

opens new frontiers to optimize future hypoxic training applications (e.g., appropriate periodization to implement isolated $\mathrm{RSH}$ and/or in combination with prolonged residence at simulated altitude) in team sports.

\section{Conclusion}

This is the first study examining psycho-physiological responses to repeated-sprint training (6 sessions) in hypoxia and normoxia in elite team-sport players over a 2 -wk inseason 'live high-train low' training camp. During the first session, hypoxia exposure during training elevated physiological and perceptual responses, whereas sprint performance (timing) was similar. Despite higher hypoxia-induced physiological stress (e.g., lower $\mathrm{SpO}_{2}$ values), improved tolerance to the hypoxic training (effective hypoxic 'acclimation') led to a decrease in perceptual responses (that were not maximal in both groups) in RSH, so as to become essentially similar to those measured in RSN. These positive adaptations could have played a role in the larger RSH-related improvement in repeated sprint performance.

\section{Acknowledgements}

This research was funded by a Grant awarded by Aspetar (Qatar Orthopedic and Sports Medicine Hospital) at the Aspire Zone Foundation, Qatar (AF/C/ASP1905/11). The authors are grateful to Mr. Julien Rysman for his help during the study. 
"Psycho-Physiological Responses to Repeated-Sprint Training in Normobaric Hypoxia and Normoxia" by Brocherie F, Millet GP, Girard O

International Journal of Sports Physiology and Performance

(C) 2016 Human Kinetics, Inc.

\section{References}

1. Girard O, Amann M, Aughey R, et al. Position statement--altitude training for improving team-sport players' performance: current knowledge and unresolved issues. Br J Sports Med. Dec 2013;47 Suppl 1:i8-16.

2. Faiss R, Girard O, Millet GP. Advancing hypoxic training in team sports: from intermittent hypoxic training to repeated sprint training in hypoxia. Br J Sports Med. Dec 2013;47 Suppl 1:i45-i50.

3. Millet GP, Faiss R, Brocherie F, Girard O. Hypoxic training and team sports: a challenge to traditional methods? Br J Sports Med. Dec 2013;47 Suppl 1:i6-i7.

4. Brocherie F, Girard O, Faiss R, Millet GP. High-intensity intermittent training in hypoxia: a double-blinded, placebo-controlled field study in youth football players. $J$ Strength Cond Res. Jan 2015;29(1):226-237.

5. Galvin HM, Cooke K, Sumners DP, Mileva KN, Bowtell JL. Repeated sprint training in normobaric hypoxia. Br J Sports Med. Dec 2013;47 Suppl 1:i74-i79.

6. Faiss R, Leger B, Vesin JM, et al. Significant molecular and systemic adaptations after repeated sprint training in hypoxia. PLoS One. 2013;8(2):e56522.

7. Gatterer H, Philippe M, Menz V, Mosbach F, Faulhaber M, Burtscher M. Shuttle-run sprint training in hypoxia for youth elite soccer players: a pilot study. J Sports Sci Med. Dec 2014;13(4):731-735.

8. Girard O, Brocherie F, Millet GP. On the use of mobile inflatable hypoxic marquees for sport-specific altitude training in team sports. Br J Sports Med. Dec 2013;47 Suppl 1:i121-i123.

9. Brocherie F, Millet GP, Hauser A, et al. "Live High-Train Low and High" Hypoxic Training Improves Team-Sport Performance. Med Sci Sports Exerc. Oct 2015;47(10):2140-2149.

10. Bishop D, Burnett A, Farrow D, Gabbett T, Newton R. Sports-science roundtable: does sports-science research influence practice? Int J Sports Physiol Perform. Jun 2006;1(2):161-168.

11. Impellizzeri FM, Rampinini E, Coutts AJ, Sassi A, Marcora SM. Use of RPE-based training load in soccer. Med Sci Sports Exerc. Jun 2004;36(6):1042-1047.

12. Eston R. Use of ratings of perceived exertion in sports. Int J Sports Physiol Perform. Jun 2012;7(2):175-182.

13. Christian RJ, Bishop DJ, Billaut F, Girard O. The role of sense of effort on selfselected cycling power output. Front Physiol. 2014;5:115.

14. Marcora S. Perception of effort during exercise is independent of afferent feedback from skeletal muscles, heart, and lungs. J Appl Physiol (1985). Jun 2009;106(6):20602062. 
"Psycho-Physiological Responses to Repeated-Sprint Training in Normobaric Hypoxia and Normoxia"

by Brocherie F, Millet GP, Girard O

International Journal of Sports Physiology and Performance

(C) 2016 Human Kinetics, Inc.

15. Billaut F, Smith K. Prolonged repeated-sprint ability is related to arterial O2 desaturation in men. Int J Sports Physiol Perform. Jun 2010;5(2):197-209.

16. Born DP, Faiss R, Willis SJ, et al. Circadian variation of salivary immunoglobin A, alpha-amylase activity and mood in response to repeated double-poling sprints in hypoxia. Eur J Appl Physiol. Aug 132016.

17. Girard O, Mendez-Villanueva A, Bishop D. Repeated-sprint ability - part I: factors contributing to fatigue. Sports Med. Aug 1 2011;41(8):673-694.

18. Foster C. Monitoring training in athletes with reference to overtraining syndrome. Med Sci Sports Exerc. Jul 1998;30(7):1164-1168.

19. Bowtell JL, Cooke K, Turner R, Mileva KN, Sumners DP. Acute physiological and performance responses to repeated sprints in varying degrees of hypoxia. J Sci Med Sport. Jul 2014;17(4):399-403.

20. Weyand PG, Lee CS, Martinez-Ruiz R, Bundle MW, Bellizzi MJ, Wright S. Highspeed running performance is largely unaffected by hypoxic reductions in aerobic power. J Appl Physiol (1985). Jun 1999;86(6):2059-2064.

21. Goods PS, Dawson BT, Landers GJ, Gore CJ, Peeling P. Effect of different simulated altitudes on repeat-sprint performance in team-sport athletes. Int J Sports Physiol Perform. Sep 2014;9(5):857-862.

22. Taylor J, Macpherson T, Spears I, Weston M. The effects of repeated-sprint training on field-based fitness measures: a meta-analysis of controlled and non-controlled trials. Sports Med. Jun 2015;45(6):881-891.

23. Girard O, Brocherie F, Morin JB, Millet GP. Neuro-mechanical determinants of repeated treadmill sprints - Usefulness of an "hypoxic to normoxic recovery" approach. Front Physiol. 2015;6:260.

24. Billaut F, Kerris JP, Rodriguez RF, Martin DT, Gore CJ, Bishop DJ. Interaction of central and peripheral factors during repeated sprints at different levels of arterial $\mathrm{O} 2$ saturation. PLoS One. 2013;8(10):e77297.

25. Aliverti A, Kayser B, Lo Mauro A, et al. Respiratory and leg muscles perceived exertion during exercise at altitude. Respir Physiol Neurobiol. Jul 31 2011;177(2):162-168.

26. Pollak KA, Swenson JD, Vanhaitsma TA, et al. Exogenously applied muscle metabolites synergistically evoke sensations of muscle fatigue and pain in human subjects. Exp Physiol. Feb 2014;99(2):368-380.

27. Amann M, Blain GM, Proctor LT, Sebranek JJ, Pegelow DF, Dempsey JA. Group III and IV muscle afferents contribute to ventilatory and cardiovascular response to rhythmic exercise in humans. J Appl Physiol (1985). Oct 2010;109(4):966-976.

28. Shibata M, Oda S, Moritani T. The relationships between movement-related cortical potentials and motor unit activity during muscle contraction. J Electromyogr Kinesiol. Jun 1997;7(2):79-85. 
"Psycho-Physiological Responses to Repeated-Sprint Training in Normobaric Hypoxia and Normoxia"

by Brocherie F, Millet GP, Girard O

International Journal of Sports Physiology and Performance

(C) 2016 Human Kinetics, Inc.

29. Townsend NE, Gore CJ, Hahn AG, et al. Living high-training low increases hypoxic ventilatory response of well-trained endurance athletes. J Appl Physiol (1985). Oct 2002;93(4):1498-1505.

30. Dempsey JA, Powell FL, Bisgard GE, Blain GM, Poulin MJ, Smith CA. Role of chemoreception in cardiorespiratory acclimatization to, and deacclimatization from, hypoxia. J Appl Physiol (1985). Apr 1 2014;116(7):858-866.

31. Millet GP, Faiss R. Hypoxic conditions and exercise-to-rest ratio are likely paramount. Sports Med. Dec 1 2012;42(12):1081-1083; author reply 1083-1085.

32. Katayama K, Fujita H, Sato K, Ishida K, Iwasaki K, Miyamura M. Effect of a repeated series of intermittent hypoxic exposures on ventilatory response in humans. High Alt Med Biol. Spring 2005;6(1):50-59.

33. Boning D. Altitude and hypoxia training--a short review. Int J Sports Med. Nov 1997;18(8):565-570.

34. Hoppeler H, Vogt M. Muscle tissue adaptations to hypoxia. J Exp Biol. Sep 2001;204(Pt 18):3133-3139. 
"Psycho-Physiological Responses to Repeated-Sprint Training in Normobaric Hypoxia and Normoxia" by Brocherie F, Millet GP, Girard O

International Journal of Sports Physiology and Performance

(c) 2016 Human Kinetics, Inc.
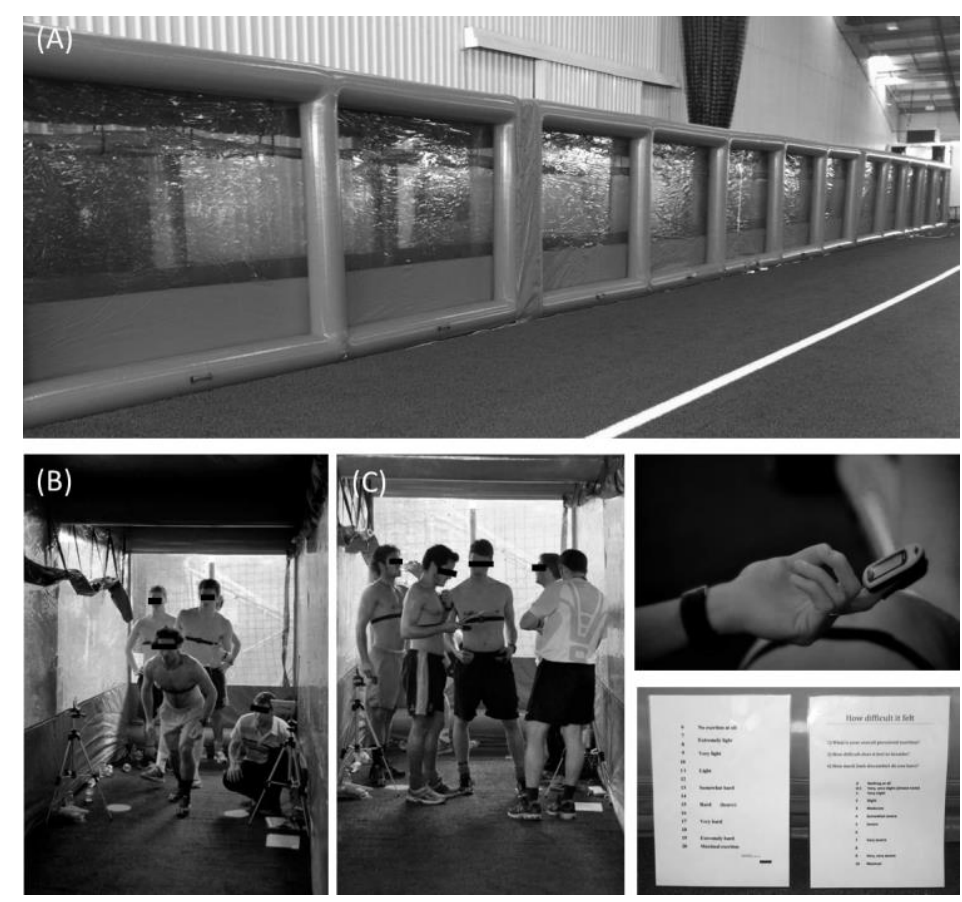

Figure 1. Illustration of the mobile inflatable simulated hypoxic equipment used for repeated-sprint training sessions. External (A, overall view of the 45-m long marquee) and inside tunnel view with players completing sprints (B) and monitoring their psychophysiological responses $(\mathrm{C})$. 
"Psycho-Physiological Responses to Repeated-Sprint Training in Normobaric Hypoxia and Normoxia" by Brocherie F, Millet GP, Girard O

International Journal of Sports Physiology and Performance

(C) 2016 Human Kinetics, Inc.

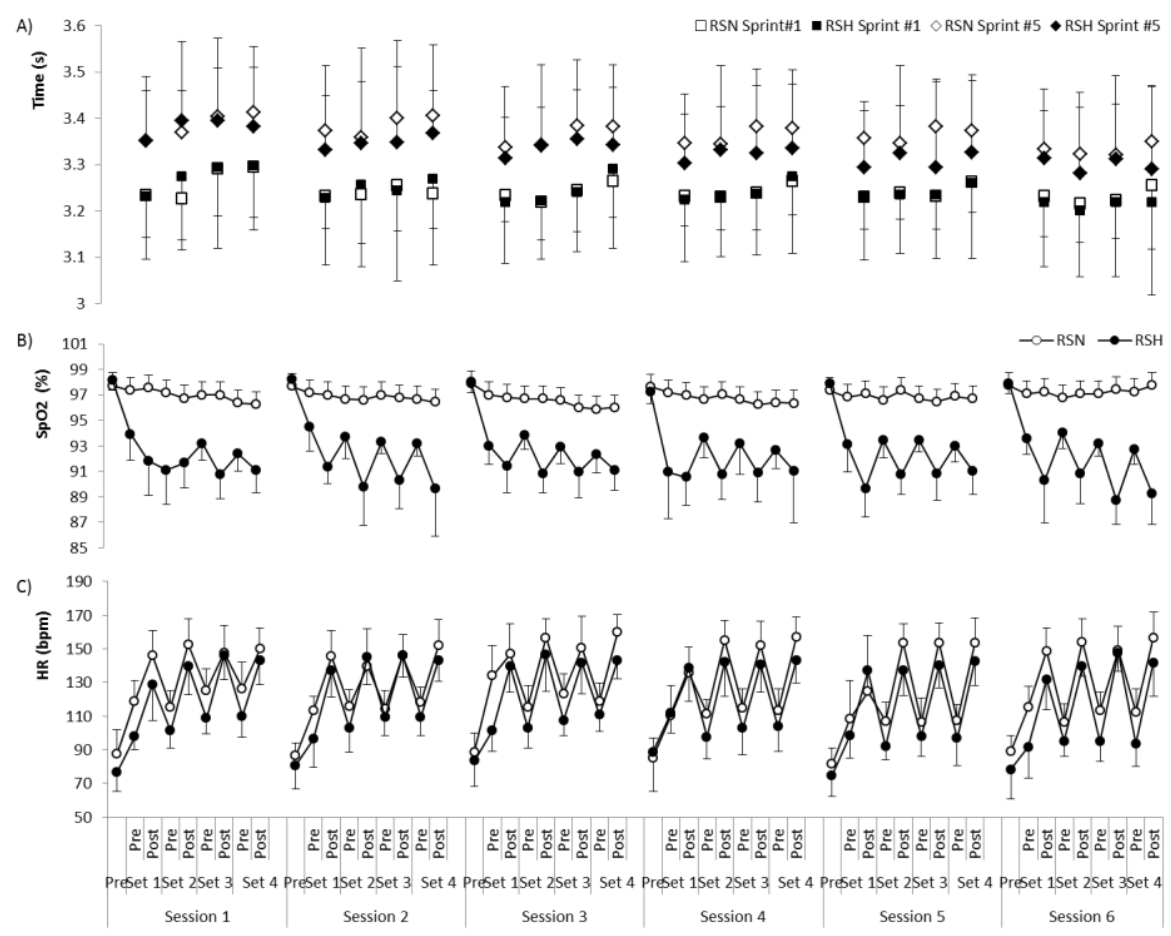

Figure 2. Sprint times (A), arterial oxyhemoglobin saturation $(\mathrm{SpO} 2 ; \mathrm{B})$ and heart rate $(\mathrm{HR}$; C) for the four sets of repeated-sprint exercise performed during each training session. Values are mean $\pm \mathrm{SD}, \mathrm{N}=23$. Data is presented for normobaric hypoxia $\left(\mathrm{RSH} ; \mathrm{FiO}_{2} \sim 14.5 \%\right)$ and normoxia ( $\left.\mathrm{RSN} ; \mathrm{FiO}_{2} 21.0 \%\right)$. 
"Psycho-Physiological Responses to Repeated-Sprint Training in Normobaric Hypoxia and Normoxia" by Brocherie F, Millet GP, Girard O

International Journal of Sports Physiology and Performance

(C) 2016 Human Kinetics, Inc.

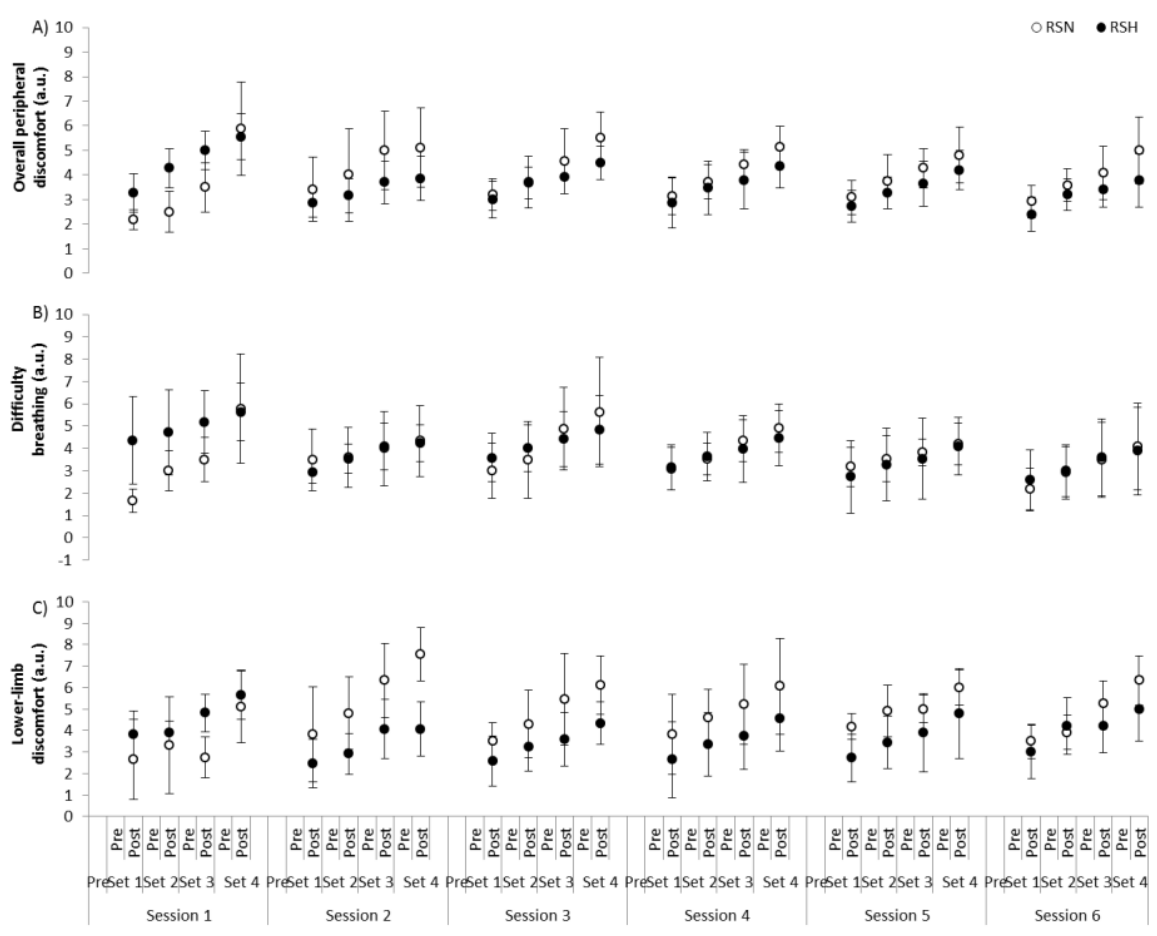

Figure 3. Ratings of overall peripheral discomfort (A), difficulty breathing (B) and lowerlimb discomfort (C) for the four sets of repeated-sprints performed during each training session. Values are mean $\pm \mathrm{SD}, \mathrm{N}=23$. Data is presented for normobaric hypoxia (RSH; $\mathrm{FiO}_{2} \sim 14.5 \%$ ) and normoxia ( $\mathrm{RSN} ; \mathrm{FiO}_{2} 21.0 \%$ ). 
"Psycho-Physiological Responses to Repeated-Sprint Training in Normobaric Hypoxia and Normoxia" by Brocherie F, Millet GP, Girard O

International Journal of Sports Physiology and Performance

(C) 2016 Human Kinetics, Inc.

Table 1. Subjects' characteristics.

\begin{tabular}{lll}
\hline & RSH $(\mathbf{n}=\mathbf{1 1})$ & RSN $(\mathbf{n}=\mathbf{1 2})$ \\
\hline Age $(\mathrm{yr})$ & $27.4 \pm 4.6$ & $24.9 \pm 4.5$ \\
\hline Height $(\mathrm{cm})$ & $178.7 \pm 8.2$ & $178.9 \pm 4.7$ \\
\hline Weight $(\mathrm{kg})$ & $77.0 \pm 7.7$ & $76.9 \pm 8.5$ \\
\hline $\mathrm{BMI}\left(\mathrm{kg} . \mathrm{m}^{-2}\right)$ & $24.1 \pm 1.6$ & $24.0 \pm 1.8$ \\
\hline $\mathrm{VO}_{2 \max }\left(\mathrm{ml} \cdot \mathrm{min}^{-1} \cdot \mathrm{kg}^{-1}\right)$ & $52.7 \pm 2.4$ & $52.5 \pm 1.8$ \\
\hline $\mathrm{HR}_{\max }($ beats.min & \\
\hline
\end{tabular}

$\mathrm{VO}_{2 \max }=$ maximal oxygen uptake; $\mathrm{HR}_{\max }=$ maximal heart rate.

Values are mean $\pm \mathrm{SD}$. 
"Psycho-Physiological Responses to Repeated-Sprint Training in Normobaric Hypoxia and Normoxia"

by Brocherie F, Millet GP, Girard O

International Journal of Sports Physiology and Performance

(C) 2016 Human Kinetics, Inc.

Table 2. Sprint performance parameters and psycho-physiological responses (average of all sets) during the 6 sessions of repeated-sprint training in hypoxia (RSH) and in normoxia (RSN).

\begin{tabular}{|c|c|c|c|c|c|c|c|c|c|c|}
\hline & \multirow[t]{2}{*}{ Training } & \multicolumn{6}{|c|}{ Session number } & \multirow[t]{2}{*}{ Average } & \multirow{2}{*}{$\begin{array}{l}\text { Changes } \\
(\%)\end{array}$} & \multirow{2}{*}{$\begin{array}{l}\text { ANOVA main } \\
\text { effects } \\
\text { (effect sizes) }\end{array}$} \\
\hline & & 1 & 2 & 3 & 4 & 5 & 6 & & & \\
\hline \multicolumn{11}{|c|}{ Sprint performance } \\
\hline \multirow{2}{*}{ Sprint time 1 (s) } & RSH & $3.27 \pm 0.14$ & $3.25 \pm 0.17$ & $3.24 \pm 0.13$ & $3.24 \pm 0.13$ & $3.24 \pm 0.13$ & $3.21 \pm 0.15$ & $3.24 \pm 0.14$ & $-1.8 \pm 3.8$ & \multirow{2}{*}{$\begin{array}{l}\mathrm{C}=0.99(0.00) \\
\mathrm{T}=0.15(0.22) \\
\mathrm{I}=0.95(0.08)\end{array}$} \\
\hline & RSN & $3.26 \pm 0.08$ & $3.24 \pm 0.08$ & $3.24 \pm 0.07$ & $3.24 \pm 0.06$ & $3.24 \pm 0.06$ & $3.23 \pm 0.09$ & $3.24 \pm 0.07$ & $-0.5 \pm 2.9$ & \\
\hline \multirow{2}{*}{ Sprint time 5 (s) } & RSH & $3.38 \pm 0.16$ & $3.35 \pm 0.19$ & $3.34 \pm 0.16$ & $3.32 \pm 0.16$ & $3.31 \pm 0.17$ & $3.30 \pm 0.16^{*}$ & $3.33 \pm 0.16 \# \# \#$ & $-2.4 \pm 3.8$ & \multirow{2}{*}{$\begin{array}{l}\mathrm{C}=0.55(0.23) \\
\mathrm{T}<0.01(0.31) \\
\mathrm{I}=0.80(0.11)\end{array}$} \\
\hline & RSN & $3.38 \pm 0.08$ & $3.38 \pm 0.08$ & $3.36 \pm 0.06$ & $3.36 \pm 0.06$ & $3.36 \pm 0.07$ & $3.33 \pm 0.09$ & $3.36 \pm 0.07$ & $-1.3 \pm 2.9$ & \\
\hline \multirow{2}{*}{ FI $(\%)$} & RSH & $4.6 \pm 1.9$ & $4.3 \pm 2.7$ & $3.9 \pm 3.2$ & $3.4 \pm 2.4$ & $3.0 \pm 2.4$ & $2.2 \pm 3.6^{*}$ & $3.6 \pm 2.8$ & $-34.1 \pm 133.9$ & \multirow{2}{*}{$\begin{array}{l}\mathrm{C}=0.16(0.32) \\
\mathrm{T}<0.05(0.44) \\
\mathrm{I}=0.99(0.07)\end{array}$} \\
\hline & $\mathrm{RSN}$ & $5.6 \pm 4.1$ & $5.4 \pm 1.2$ & $4.6 \pm 2.3$ & $4.5 \pm 1.9$ & $4.4 \pm 2.5$ & $3.6 \pm 3.3^{*}$ & $4.6 \pm 2.7$ & $-62.7 \pm 127.7$ & \\
\hline \multicolumn{11}{|c|}{ Physiological responses } \\
\hline \multirow{2}{*}{$\mathrm{SpO}_{2}(\%)$} & $\mathrm{RSH}$ & $92.0 \pm 1.6 \# \# \#$ & $92.0 \pm 1.4 \# \# \#$ & $92.0 \pm 1.1 \# \# \#$ & $91.9 \pm 1.0 \# \# \#$ & $91.9 \pm 0.9 \# \# \#$ & $91.7 \pm 1.2 *$,\#\#\# & $91.9 \pm 1.2 \# \# \#$ & $-0.9 \pm 1.4$ & \multirow{2}{*}{$\begin{array}{l}\mathrm{C}<0.001(3.48) \\
\mathrm{T}<0.001(0.42) \\
\mathrm{I}<0.001(0.39)\end{array}$} \\
\hline & RSN & $97.0 \pm 0.5$ & $96.8 \pm 0.6$ & $96.5 \pm 0.6$ & $96.7 \pm 0.4$ & $96.8 \pm 0.7$ & $97.3 \pm 0.6$ & $96.9 \pm 0.6$ & $0.2 \pm 0.6$ & \\
\hline \multirow{2}{*}{ HR (bpm) } & RSH & $142 \pm 13$ & $144 \pm 13$ & $143 \pm 10$ & $141 \pm 13$ & $139 \pm 11$ & $138 \pm 14$ & $140 \pm 12$ & $0.7 \pm 12.9$ & \multirow{2}{*}{$\begin{array}{l}\mathrm{C}=0.053(0.53) \\
\mathrm{T}=0.11(0.35) \\
\mathrm{I}=0.55(0.23)\end{array}$} \\
\hline & RSN & $148 \pm 13$ & $145 \pm 12$ & $153 \pm 14$ & $145 \pm 11$ & $143 \pm 13$ & $150 \pm 13$ & $147 \pm 12$ & $0.9 \pm-9.8$ & \\
\hline \multicolumn{11}{|c|}{ Perceptual responses } \\
\hline \multirow{2}{*}{ RPE (a.u.) } & $\mathrm{RSH}$ & $14.6 \pm 0.8$ & $13.3 \pm 0.9$ & $14.1 \pm 1.0$ & $14.1 \pm 1.3$ & $13.8 \pm 1.7$ & $13.1 \pm 1.3$ & $13.8 \pm 1$ & $-10.5 \pm 15.4 \#$ & \multirow{2}{*}{$\begin{array}{l}\mathrm{C}<0.05(0.61) \\
\mathrm{T}=0.31(0.28) \\
\mathrm{I}=0.09(0.37)\end{array}$} \\
\hline & RSN & $14.4 \pm 2.6$ & $14.1 \pm 1.9$ & $14.3 \pm 1.8$ & $14.1 \pm 0.9$ & $14.3 \pm 1.9$ & $14.8 \pm 0.9$ & $14.3 \pm 1.7$ & $4.0 \pm 17.7$ & \\
\hline Overall & $\mathrm{RSH}$ & $4.5 \pm 0.8 \#$ & $3.4 \pm 0.7 * *$ & $3.8 \pm 0.7 * *$ & $3.6 \pm 1.0 * *$ & $3.5 \pm 0.8 * *$ & $3.2 \pm 0.8 * * *$ & $3.7 \pm 0.8 \#$ & $-28.5 \pm 22.4 \#$ & $C<0.05(0.55)$ \\
\hline
\end{tabular}


"Psycho-Physiological Responses to Repeated-Sprint Training in Normobaric Hypoxia and Normoxia"

by Brocherie F, Millet GP, Girard O

International Journal of Sports Physiology and Performance

(C) 2016 Human Kinetics, Inc.

\begin{tabular}{|c|c|c|c|c|c|c|c|c|c|c|}
\hline \multirow[b]{3}{*}{$\begin{array}{l}\text { peripheral } \\
\text { discomfort } \\
\text { (a.u.) }\end{array}$} & \multirow[t]{2}{*}{ Training } & \multicolumn{6}{|c|}{ Session number } & \multirow[t]{2}{*}{ Average } & \multirow{2}{*}{$\begin{array}{l}\text { Changes } \\
(\%)\end{array}$} & \multirow{3}{*}{$\begin{array}{l}\begin{array}{l}\text { ANOVA main } \\
\text { effects } \\
\text { (effect sizes) } \\
\mathrm{T}<0.001(0.62) ; \\
\mathrm{I}=0.61(0.21)\end{array}\end{array}$} \\
\hline & & 1 & 2 & 3 & 4 & 5 & 6 & & & \\
\hline & RSN & $3.5 \pm 1.0$ & $4.4 \pm 1.6$ & $4.2 \pm 1.0$ & $4.1 \pm 0.7$ & $4.0 \pm 0.9$ & $43.9 \pm 0.9$ & $4.0 \pm 1.0$ & $-2.7 \pm 51.9$ & \\
\hline \multirow{2}{*}{$\begin{array}{l}\text { Difficulty } \\
\text { breathing (a.u.) }\end{array}$} & RSH & $5.0 \pm 1.6$ & $3.7 \pm 0.8^{*}$ & $4.2 \pm 1.2 *$ & $3.8 \pm 1.2 *$ & $3.4 \pm 1.6 * *$ & $3.3 \pm 1.5 * * *$ & $3.9 \pm 1.3$ & $-33.8 \pm 25.7$ & \multirow{2}{*}{$\begin{array}{l}\mathrm{C}=0.68(0.12) \\
\mathrm{T}<0.001(0.69) \\
\mathrm{I}=0.72(0.18)\end{array}$} \\
\hline & RSN & $3.5 \pm 1.2$ & $3.9 \pm 1.5$ & $4.3 \pm 1.8$ & $4.0 \pm 0.9$ & $3.7 \pm 0.9$ & $3.2 \pm 1.4$ & $3.7 \pm 1.3$ & $-26.3 \pm 31.4$ & \\
\hline \multirow{2}{*}{$\begin{array}{l}\text { Lower-limb } \\
\text { discomfort } \\
\text { (a.u.) }\end{array}$} & $\mathrm{RSH}$ & $4.5 \pm 0.9 \#$ & $3.4 \pm 1.2 * * *$ \#\#\# & $3.4 \pm 1.1 * *$,\#\# & $3.6 \pm 1.6^{* *}$,\#\# & $3.7 \pm 1.6^{*}, \#$ & $4.1 \pm 1.3$ & $3.8 \pm 1.3 \# \# \#$ & $-9.5 \pm 34.0 \#$ & \multirow{2}{*}{$\begin{array}{l}\mathrm{C}<0.001(0.84) \\
\mathrm{T}=0.60(0.21) \\
\mathrm{I}<0.05(0.41)\end{array}$} \\
\hline & RSN & $3.5 \pm 1.7$ & $5.6 \pm 1.7 * * *$ & $4.8 \pm 1.5^{* *}$ & $4.9 \pm 1.8 * * *$ & $5.0 \pm 0.8 * * *$ & $4.8 \pm 1.0 * *$ & $4.8 \pm 1.4$ & $26.5 \pm 78.0$ & \\
\hline
\end{tabular}

Notes: Values are mean \pm SD. C, T, I-condition, time and interaction effects, respectively.

$*$ significantly different from session number $1, \mathrm{P}<0.05, * *<0.01, * * *<0.001$. \# significantly different from RSN, P $<0.05, \# \# \# 0.001$. 